\title{
Diffusion Tensor Imaging of Skeletal Muscle - Correlation of Fractional Anisotropy to Muscle Power
}

\author{
Diffusions-Tensor Imaging des Skelettmuskels: Korrelation von fraktioneller \\ Anisotropie mit mechanischen Muskelleistung
}

Authors

Affiliations
M. Scheel' ${ }^{1}$ T. Prokscha', P. von Roth ${ }^{2}$, T. Winkler ${ }^{2}$, R. Dietrich ${ }^{3}$, S. Bierbaum ${ }^{3}$, A. Arampatzis ${ }^{3}$, G. Diederichs ${ }^{1}$

Department of Radiology, Charité - Universitätsmedizin Berlin, Germany

2 Orthopaedic Department, Center for Musculoskeletal Surgery, Charité - Universitätsmedizin Berlin, Germany

Department of Training and Movement Sciences, Center for Sport Science and Sports Medicine Berlin, Humbold-

$\mathrm{t}$-University Berlin, Germany
Key words

- MR-diffusion/perfusion

- MR-imaging

- diagnostic radiology

eingereicht 14.1.2013

akzeptiert 21.5.2013

Bibliography

Dol http://dx.doi.org/

10.1055/s-0033-1335911

Published online: 25.7.2013

Fortschr Röntgenstr 2013; 185:

857-861 @ Georg Thieme

Verlag KG Stuttgart · New York .

ISSN 1438-9029

\section{Correspondence}

Dr. Michael Scheel

Department of Radiology,

Charité - Universitätsmedizin

Berlin, Germany

Charitéplatz 1

10117 Berlin

Germany

Tel.: ++ 49/30/450527102

Fax: ++49/30/450527902

michael.scheel@charite.de

\section{Abstract \\ $\nabla$}

Purpose: Recent DTI studies demonstrated the possibility of fiber geometry visualization in skeletal muscle. We tested for an association between muscle power and standard DTI parameters, e.g. fractional anisotropy. Materials and Methods: Maximal muscle power (Lmax) of the soleus muscle was determined in 11 healthy subjects. Subsequently DTI was performed and standard parameters (fractional anisotropy - FA, mean diffusivity - MD, parallel diffusivity $\mathrm{PD}$, radial diffusivity - RD) were extracted in an ROI of the soleus muscle.

Results: We found a signficant association of Lmax with FA (neg. correlation: $r=-0.85$, $\mathrm{p}=0.0015$ ) and RD (pos. correlation $\mathrm{r}=0.80$, $\mathrm{p}=0.047$ ). There was no signficant association of MD or PD.

Conclusion: Maximum muscle power is an indirect measure of fiber type distribution. The correlation between muscle power and DTI parameters can be explained by differences in fiber diameter and differences in the intracellular microstructure of type- 1 and type- 2 fibers. DTI should be evaluated as a tool for non-invasive quantification of fiber type distribution in skeletal muscle.

Key Points:

- Fractional anisotropy is negatively correlated with maximum power of a muscle.

- An explanation is the association of fractional anisotropy with muscle fiber distribution.

- DTI might facilitate non-invasive assessment of fiber type distribution in skeletal muscle.

Citation Format:

- Scheel M, Prokscha T, von Roth P etal. Diffusion Tensor Imaging of Skeletal Muscle Correlation of Fractional Anisotropy to
Muscle Power. Fortschr Röntgenstr 2013; $857-861$

\section{Zusammenfassung $\nabla$}

Ziel: Studien der letzten Jahre haben gezeigt, dass mit Diffusions-Tensor Imaging die Fasergeometrie von Skelettmuskeln dargestellt werden kann. Ziel der aktuellen Studie war es zu überprüfen, ob auch zwischen funktioneller Muskelleistung und Standard DTI-Parametern, wie z.B. der Fraktionellen Anisotropie (FA) Korrelationen bestehen. Material und Methoden: Bei 11 gesunden Probanden wurde zunächst die maximale mechanische Leistung (Lmax) des M. soleus bestimmt. Im Anschluss wurde bei allen Probanden DTI Messungen durchgeführt und die Standard DTI Parameter (Fraktionelle Anisotropie - FA, Mittlere Diffusivität - MD, Parallel Diffusivität - PD, Radiale Diffusivität - RD) über eine ROI Analyse im M. soleus quantifiziert.

Ergebnisse: Es bestand eine signifikante Assoziation zwischen Lmax und FA (negative Korrelation $\mathrm{r}=-0.85, \mathrm{p}=0.0015$ ) bzw. RD (positive Korrelation $r=0.80, p=0.047)$. Kein signifikanter Zusammenhang bestand zu MD oder PD.

Schlussfolgerungen: Die maximale mechanische Muskelleistung ist ein indirekter Parameter für die Muskelfaserzusammensetzung. Die gefundenen Korrelation zwischen Muskelleistung und DTI Parametern können durch Unterschiede im Faserdurchmesser und Unterschiede in der intrazellulären Mikrostruktur von Typ-1 und Typ-2 Fasern erklärt werden. DTI eignet sich möglicherweise als nicht-invasive Methode zur Bestimmung der Muskelfaserzusammensetzung. 


\section{Introduction}

$\nabla$

Diffusions-Tensor-Imaging (DTI) is an MRI method facilitating microstructural examination of biological tissues. The most commonly known clinical application of DTI would certainly be the imaging of brain fibre tracts for optimizing the planning of radiation therapy or surgery, for example. However, DTI also enables very early detection of potential changes associated with neurodegenerative diseases (e.g., Alzheimer's, dementia, amyotrophic lateral sclerosis) [1 - 3]. What is less known is that DTI can also be used to examine the microarchitecture of organs other than those of the central nervous system. For example, one of the first biological tissues demonstrated using DTI was not cerebral white matter, but rather the skeletal muscle of a porcine loin [4]. It thus comes as no surprize that DTI has also been used for examining muscle tissue for the past several years. A series of studies has shown that DTI can be used to visualize the fibre geometry of the muscles of the extremities or the pelvic floor [5 - 7]. Furthermore, DTI has been used in diagnosing various muscle pathologies, e.g., denervation or muscle ischemia [8-10]. For a summary of the significance of MRI and DTI examination in analysing muscle tissue, those interested are advised to refer to the appropriate survey articles [11-14].

The human skeletal muscle is divided into two basic types of fibres having key differences in terms of function and microstructure. Type-1 fibres contract slowly and are endowed with major endurance owing to their mitochondria, myoglobin, capillaries and, above all, oxidative metabolism. Type-2 fibres, in contrast, contract rapidly, exhibit higher maximum muscle performance and, having less myoglobin and fewer capillaries, rely on anaerobic metabolism, which leads more quickly to exhaustion. Because both fibre types differ in both average fibre diameter and microstructural intracellular makeup, it can be assumed that these differences result in different diffusion coefficients that are great enough to be measured by DTI.

The quantity of type- 1 and type- 2 fibres in a muscle influence the functional performance parameters thereof, such as maximum mechanical muscle power [15]. Type-2 muscle fibres exhibit a maximum mechanical power up to three times greater than that of their counterparts [16].

Our study thus hypothesized that there would have to be an association between DTI parameters and muscle performance. The aim of the study was to test whether there are correlations between the standard DTI parameters of the soleus muscle and the maximum mechanical power thereof in healthy test subjects.

\section{Material and methods}

$\nabla$

\section{Test subjects}

Following approval by the local ethics committee, 11 male subjects were recruited for the study $(\mathrm{BMI}=23.5 \pm 3.1$; age $=27.2 \pm 10.7$ - all test subjects were involved in sports as a leisure activity). The maximum mechanical power of the soleus muscle was initially ascertained in all test subjects. DTI-measurement was then performed in intervals not exceeding 10 day (see below for details).

\section{Ascertaining maximum mechanical power}

To ascertain the maximum mechanical power $\left(\mathrm{L}_{\max }\right)$ of the soleus muscle, isokinetic maximum plantarflexion strength was measured on a dynamometer (Biodex System 3, Biodex Medical Systems, New York, USA) using a sharply bent knee angle of approximately $40^{\circ}$ ( $\bullet$ Fig. 1 ). In this position, the muscle length of the gastrocnemii muscles is in a functional range in which no significant contraction can be produced [17]. The measured torque is thus generated almost exclusively by the soleus muscle. A total of seven different angular velocities $\left(60,90,120,150,180,210\right.$ und $\left.240^{\circ} / \mathrm{s}\right)$ was measured, since maximum mechanical power is achieved in this range. Following a warm-up period, the test subjects performed isokinetic contractions at various angular velocities in randomized order. Prior to each contraction, the rotational axis of the dynamometer and the ankle were aligned. During the maximal isokinetic contractions, however, the rotational axes shifted despite the foot being fixed into position. The measured torques therefore do not equal the resulting torques of the ankle[18]. Ankle angle and ankle angular velocity were thus additionally recorded using a movement analysis system (Vicon Motion Systems, Los Angeles, USA), and the corrected resulting ankle torque was computed by means of inverse dynamics $[17,18]$.

\section{MRI measurement and evaluation}

All measurements were performed on a $1.5 \mathrm{~T}$ Avanto (gradient system with a maximal amplitude $=45 \mathrm{mT} / \mathrm{m}$ and a maximal slew rate $=200 \mathrm{Tm}^{-1} \mathrm{~s}^{-1}-$ Siemens, Erlangen) with a flexible extremities coil (4-channel flex coil). The ankle was fixed at $90^{\circ}$, while cushioning beneath the heel and knee ensured comfort and prevented the compression of the muscles of the lower leg.

The measurement protocol consisted of a high-resolution T1-weighted turbo spin-echo-sequence $(\mathrm{TR} / \mathrm{TE}=626 / 11 \mathrm{~ms}$, $\mathrm{FOV}=180 \mathrm{~mm}$, resolution $=0.7 \times 0.7 \mathrm{~mm}$, slice thickness $=$ $6 \mathrm{~mm}$, measurement time $=2: 54 \mathrm{~min}$ ) and a single-shot-EPIDTI-sequence $(\mathrm{TR} / \mathrm{TE}=3400 / 79 \mathrm{~ms}, \mathrm{FOV}=192 \mathrm{~mm}$, resolution $=3.0 \times 3.0 \mathrm{~mm}$, slice thickness $=3 \mathrm{~mm}$, measurement time $=4: 37 \mathrm{~min}$, acceleration by means of parallel imaging

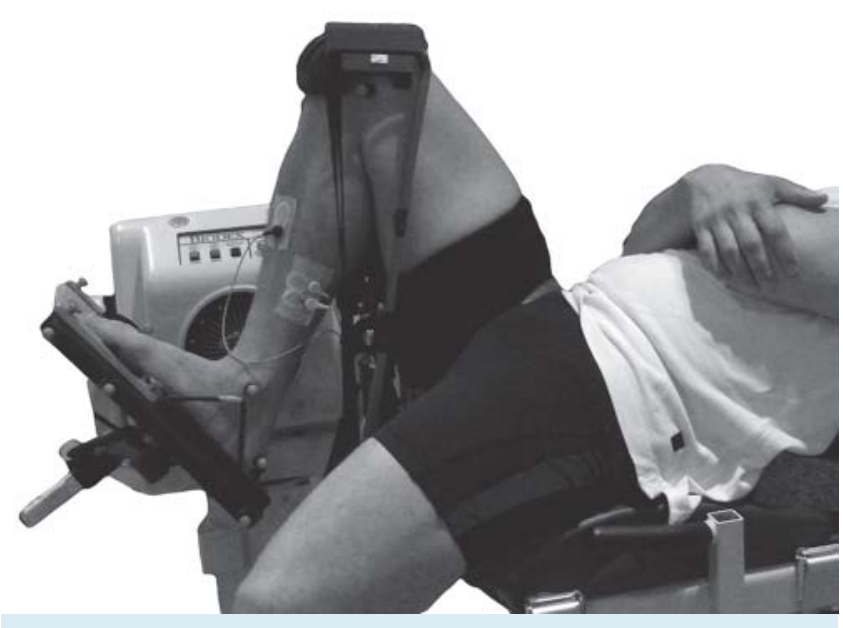

Fig. 1 Setup for maximal mechanical power measurement during plantar flexion. Measurements were performed with knees bend to minimise the effect of gastrocnemic muscle and selectively determine the power of the soleus muscle. 
GRAPPA factor $=2$ ). In this process, b-values of 0 and $600 \mathrm{~s} /$ $\mathrm{mm}^{2}$ were used in 12 directions. A study conducted by Saupe et al. found a b-value of $600 \mathrm{~s} / \mathrm{mm}^{2}$ to be the optimal b-value for muscle DTI at $1.5 \mathrm{~T}$. [19]. To increase the SNR (signal-tonoise ratio) the DTI sequence was repeated a total of 6 times and averaged over the further course of the analyses. Using a test subject as example, $\bullet$ Fig. 2 shows the T1-weighting, the image with a b-value of $0 \mathrm{~s} / \mathrm{mm}^{2}$ of the DTI sequence(b0-image) and the DTI parameter cards (FA, MD, PD, RD).

Analysis of DTI data was performed using the software FSL (FMRIB Software Library, Oxford, UK) and involved a preprocessing of the data with corrections being made for movement and eddy current distortions. The tensor-computation was then performed by means of a Linear-LeastSquare-Fit using the averaged raw data, and the corresponding standard DTI parameter maps were computed. The most commonly known of these are mean diffusivity (MD - mean of the eigenvalues of the diffusion ellipsoid) and fractional anisotropy (FA). FA describes the diffusionanisotropy, i. e., the degree to which the diffusion profile is aligned, and can range from 0 (isotropic - equally strong diffusion in all direction) to 1 (maximal anisotropic - diffusion only in one direction) [20]. Additional DTI parameters that were computed include parallel diffusivity (PD - equals the longest ellipsoid eigenvalue) and radial diffusivity (RD average of the medium and shortest ellipsoid).

Using the high-resolution $\mathrm{T} 1$, a region of interest (ROI) was manually plotted for the soleus muscle ( $\bullet$ Fig. 2 ) and co-registered on the DTI data (ROI-size $=990 \pm 303 \mathrm{~mm}^{2}-$ mean \pm standard deviation). From this ROI, means were computed for the respective parameters for each test subject and used for further correlation analyses.

\section{Statistical analysis}

An association was performed between maximal mechanical power and the various DTI parameters using a non-parametric Spearman correlation analysis (Software Prism 5, GraphPad). Because of the relatively small number of cases, a non-parametric test was selected. A p-value $<0.05$ was regarded as statistically significant.
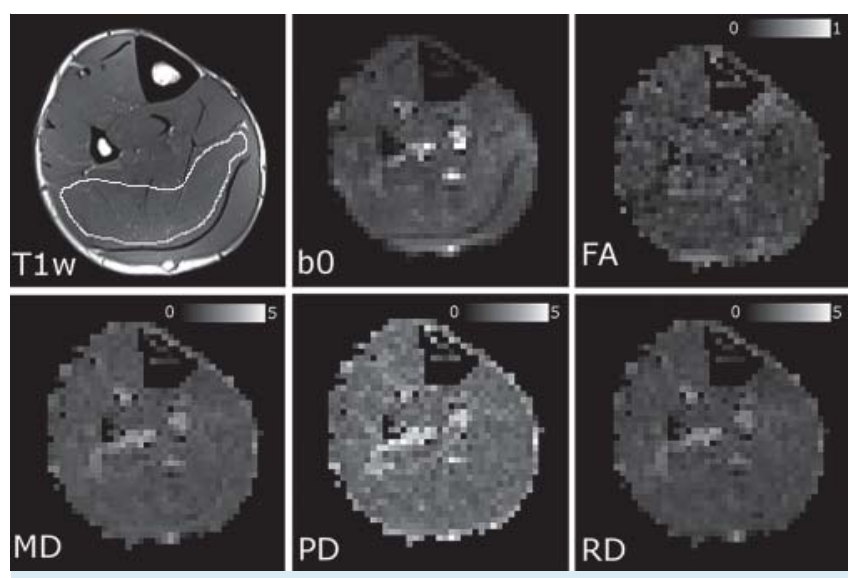

Fig. 2 Example images for T1w (including outline of M. soleus ROI), DWImage with b-value $=0 \mathrm{~s} / \mathrm{mm}^{2}$ and the DTI parametermaps (FA - fractional anisotropy, MD - mean diffusivity, PD - parallel diffusivity, RD - radial diffusivity). MD, PD and RD in $\mu \mathrm{m}^{2} / \mathrm{s}$.

\section{Results}

$\nabla$

The maximum mechanical power $\mathrm{L}_{\max }$ of the soleus muscle was $139 \pm 40$ Watts (mean \pm standard deviation). $\odot$ Table 1 and $\odot$ Fig. 3 present the descriptive statistics and the correlations of the various DTI parameters. There was a significant negative correlation between $L_{\max }$ and $F A(r=-0.85$, $\mathrm{p}=0.0015$ ). In contrast, there was positive correlation between $\mathrm{L}_{\max }$ and $\mathrm{RD}(\mathrm{r}=0.80, \mathrm{p}=0.0047)$. $\mathrm{PD}$ and MD showed no significant correlations.

\section{Discussion \\ $\nabla$}

The present study demonstrated a significant connection between maximal mechanical power $\mathrm{L}_{\max }$ and DTI-parameters FA and RD in the soleus muscle. The MD and PD exhibited no significant connection with muscle power.

In principle, a higher mechanical power would suggest a higher portion of type- 2 fibres. Compared to their type- 1 counterparts, these fibres have on average a greater diameter and lower mitochondrial density [21]. These two facts could account for the elevated RD we observed, which would in turn also explain the lower FA values.

However, DTI parameters are influenced by a series of other factors. In particular the b-value of a DTI measurement, which is directly related to diffusion time, has a decisive influence on structural sensitivity, i. e., which particular cellular structures could be influenced by the measured diffusion. Diffusion times in typical DTI sequences range from 20 to $40 \mathrm{~ms}$. This means an average diffusion distance ranging between 20 and $27 \mu \mathrm{m}$. In this context, it becomes clear that in addition to fibre diameter, in other words restriction of diffusion through the cell membrane, intracellular barriers would also have to decisively influence the measured diffusion rates. This has already been demonstrated in an in-vitro study performed on skeletal muscle fibres [22].

Developing a non-invasive way of quantifying fibre types in a muscle would be interesting not only for monitoring physical training in competitive sports, but also for diagnosing and evaluating the course of muscle diseases. The gold standard for determining muscle fibre composition is a combination of muscle biopsy and histological study. Due to the invasive nature of these methods, this procedure is very rarely performed, being employed only under special circumstances, and should naturally be avoided particularly in the case of healthy athletes.

Of course, the measurement of muscle strength is only an indirect parameter for the portion of muscle fibre types

Table 1 Correlation between DTI parameters (fractional anisotropy - FA, mean diffusivity - MD, parallel diffusivity - PD, radial diffusivity - RD) and maximal power $\mathrm{L}_{\max }$.

\begin{tabular}{|llll|} 
& $\begin{array}{l}\text { mean } \pm \text { standard } \\
\text { deviation }\end{array}$ & $\begin{array}{l}\text { Spearman correlation } \\
\text { coefficient }\end{array}$ & p-value \\
\hline $\mathrm{FA}$ & $0.26 \pm 0.03$ & -0.85 & $0.0015^{1}$ \\
\hline $\mathrm{MD}$ in $\mu \mathrm{m}^{2} / \mathrm{s}$ & $1.57 \pm 0.04$ & 0.55 & 0.0876 \\
\hline $\mathrm{PD}$ in $\mu \mathrm{m}^{2} / \mathrm{s}$ & $2.01 \pm 0.05$ & -0.31 & 0.3560 \\
\hline $\mathrm{RD}$ in $\mu \mathrm{m}^{2} / \mathrm{s}$ & $1.35 \pm 0.06$ & 0.80 & 0.0047 \\
\hline
\end{tabular}

1 significance at $\mathrm{p}<0.01$ 

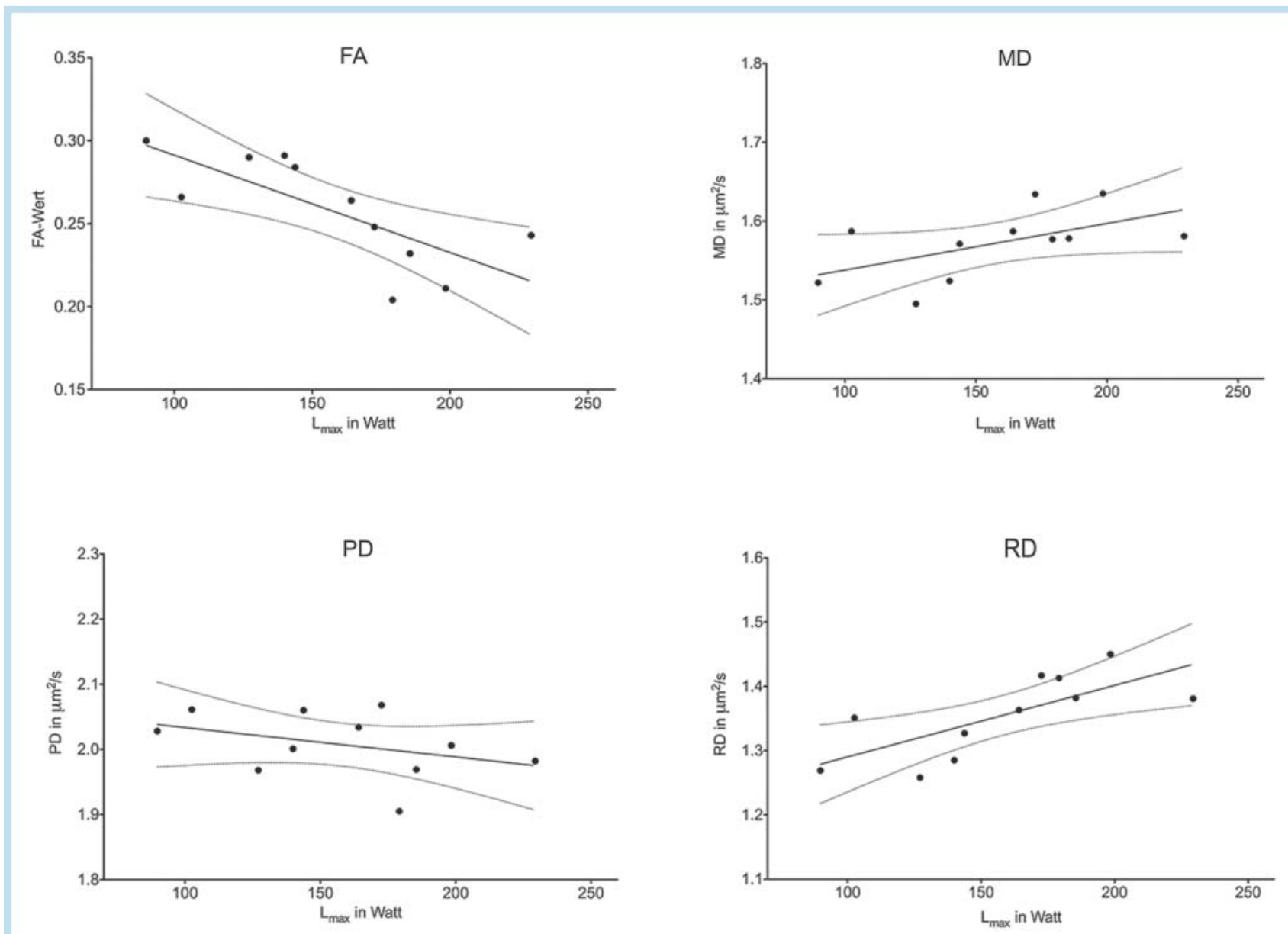

Fig. 3 Correlation of maximal mechanical power in watt with fractional anisotropy (FA), mean diffusivity (MD), parallel diffusivity (PD) and radial diffusivity (RD). MD, PD und RD in $\mu \mathrm{m}^{2} / \mathrm{s}$.

and cannot replace the gold standard of an invasive muscle biopsy. Nevertheless, this study was able to show that there is a connection between the mechanical power of a muscle and diffusivity. Further research shall be required to determine whether or not it will be possible in the future for DTI measurements to predict the strength or training status of a muscle. Our cohort consisted exclusively of healthy, young men, and we conducted strength measurements in only in one muscle. Future studies shall demonstrate to what extent our results can be generalized to other muscle groups and test subjects. It has also been reported that DTI parameters vary depending on muscle examined [23-26], sex and age $[27,28]$. DTI parameters also vary with passive and active changes in muscle length $[29,30]$.The intra-individual reliability of DTI parameters of skeletal muscle also warrant further examination. Nonetheless, the initial studies in this area have been highly promising [31].

To what extent DTI is effective as a non-invasive method for determining muscle fibre composition shall be the subject of future studies. It shall also be interesting to see what type of advantages and disadvantages DTI examination of muscle tissue poses relative to other advanced MRI (e.g. MR-spectroscopy) and to what extent the newly available combination of MRI and PET shall change the diagnosing of muscle diseases [32, 33]. In summary, our study has shown that DTI parameters of the soleus muscle have significant correlations with muscle-specific performance.

\section{Acknowledgement}

This manuscript is dedicated to Professor Bernd Hamm for his 60th birthday.

\section{Literatur}

1 Matthews PM, Filippini N, Douaud G. Brain Structural and Functional Connectivity and the Progression of Neuropathology in Alzheimer's Disease. J Alzheimers Dis 2013; 33: S163-S172

2 Turner MR, Agosta F, Bede P et al. Neuroimaging in amyotrophic lateral sclerosis. Biomark Med 2012; 6: 319-337

3 Sunaert S, Sage C, Peeters $R$ et al. Vascular versus neuronal defects in ALS: an fMRI and DTI study. Fortschr Röntgenstr 2006; 178: . DOI: $10.1055 / \mathrm{s}-2006-931855$

4 Basser PJ, Mattiello J, LeBihan D. MR diffusion tensor spectroscopy and imaging. Biophys J 1994; 66: 259-267

5 Sinha U, Sinha S, Hodgson JA et al. Human soleus muscle architecture at different ankle joint angles from magnetic resonance diffusion tensor imaging. J Appl Physiol 2011; 110: 807 - 819

6 Zijta FM, Froeling M, Van der Paardt MP et al. Feasibility of diffusion tensor imaging (DTI) with fibre tractography of the normal female pelvic floor. Eur Radiol 2011; 21: 1243-1249 
7 Froeling M, Nederveen AJ, Heijtel DFR et al. Diffusion-tensor MRI reveals the complex muscle architecture of the human forearm. J Magn Reson Imaging 2012; 36: 237-248

8 Heemskerk AM, Strijkers GJ, Drost MR et al. Skeletal muscle degeneration and regeneration after femoral artery ligation in mice: monitoring with diffusion MR imaging. Radiology 2007; 243: 413-421

9 Zaraiskaya T, Kumbhare D, Noseworthy MD. Diffusion tensor imaging in evaluation of human skeletal muscle injury. J Magn Reson Imaging 2006; 24: 402-408

10 Yamabe E, Nakamura T, Oshio $\mathrm{K}$ et al. Line scan diffusion spectrum of the denervated rat skeletal muscle. J Magn Reson Imaging 2007; 26: $1585-1589$

11 Noseworthy $M D$, Davis $A D$, Elzibak AH. Advanced MR imaging techniques for skeletal muscle evaluation. Semin Musculoskelet Radiol 2010; 14: 257-268

12 Strijkers GJ, Drost MR, Nicolay K. Diffusion Imaging in Muscle. Diffusion MRI: Theory, Methods, and Applications. 1st ed. Oxford University Press; 2010: 672-689

13 Wörtler K, Heuck A. Arbeitsgemeinschaft Muskuloskelettale Radiologie. Fortschr Röntgenstr 2011; 183: 1016-1018

14 Langner S, Schroeder HW, Hosten $N$ et al. Diagnostik neurovaskulärer Kompressionssyndrome. Fortschr Röntgenstr 2012; 184: 220-228

15 Bottinelli $R$, Betto $R$, Schiaffino $S$ et al. Unloaded shortening velocity and myosin heavy chain and alkali light chain isoform composition in rat skeletal muscle fibres. J Physiol 1994; 478: 341 -349

16 Bottinelli $R$, Schiaffino S, Reggiani C. Force-velocity relations and myosin heavy chain isoform compositions of skinned fibres from rat skeletal muscle. J Physiol 1991; 437: 655-672

17 Arampatzis A, De Monte G, Morey-Klapsing G. Effect of contraction form and contraction velocity on the differences between resultant and measured ankle joint moments. J Biomech 2007; 40: 1622-1628

18 Arampatzis A, Morey-Klapsing G, Karamanidis $K$ et al. Differences between measured and resultant joint moments during isometric contractions at the ankle joint. J Biomech 2005; 38: 885-892

19 Saupe N, White LM, Stainsby J et al. Diffusion tensor imaging and fiber tractography of skeletal muscle: optimization of B value for imaging at 1. 5 T. Am J Roentgenol 2009; 192: W282 -W290

20 Pierpaoli C, Basser PJ. Toward a quantitative assessment of diffusion anisotropy. Magn Reson Med 1996; 36: 893-906
21 Ogata T, Yamasaki Y. Ultra-high-resolution scanning electron microscopy of mitochondria and sarcoplasmic reticulum arrangement in human red, white, and intermediate muscle fibers. Anat Rec 1997; 248: 214-223

22 Kinsey ST, Locke BR, Penke B et al. Diffusional anisotropy is induced by subcellular barriers in skeletal muscle. NMR Biomed 1999; 12: 1-7

23 Galbán CJ, Maderwald S, Uffmann K et al. Diffusive sensitivity to muscle architecture: a magnetic resonance diffusion tensor imaging study of the human calf. Eur. J Appl Physiol 2004; 93: 253-262

24 Sinha S, Sinha $U$, Edgerton VR. In vivo diffusion tensor imaging of the human calf muscle. J Magn Reson Imaging 2006; 24: 182-190

25 BudzikJF, Le ThucV, Demondion X et al. In vivo MR tractography of thigh muscles using diffusion imaging: initial results. Eur Radiol 2007; 17: 3079-3085

26 Karampinos DC, King KF, Sutton BP et al. In vivo study of cross-sectional skeletal muscle fiber asymmetry with diffusion-weighted MRI. Conf Proc IEEE Eng Med Biol Soc 2007; 2007: 327 - 330

27 Galbán CJ, Maderwald S, Uffmann $K$ et al. A diffusion tensor imaging analysis of gender differences in water diffusivity within human skeletal muscle. NMR Biomed 2005; 18: 489-498

28 Galbán CJ, Maderwald S, Stock $F$ et al. Age-related changes in skeletal muscle as detected by diffusion tensor magnetic resonance imaging. J Gerontol A Biol Sci Med Sci 2007; 62: 453-458

29 Schwenzer NF, Steidle G, Martirosian P et al. Diffusion tensor imaging of the human calf muscle: distinct changes in fractional anisotropy and mean diffusion due to passive muscle shortening and stretching. NMR Biomed 2009; 22: 1047 - 1053

30 Okamoto Y, Kunimatsu A, Kono T et al. Changes in MR diffusion properties during active muscle contraction in the calf. Magn Reson Med Sci 2010; 9: $1-8$

31 Sinha S, Sinha $U$. Reproducibility analysis of diffusion tensor indices and fiber architecture of human calf muscles in vivo at 1.5 Tesla in neutral and plantarflexed ankle positions at rest. J Magn Reson Imaging 2011; 34: 107-119

32 Schwenzer NF, Pfannenberg C, Reischl G et al. Einsatz von MR/PET in der onkologischen Bildgebung. Fortschr Röntgenstr 2012; 184: 780 - 787

33 Petritsch B, Köstler H, Machann W et al. Nicht-Invasive Bestimmung des myocardial Lipidgehalts bei M. Fabry mittels 1H-MR Spectroscopy. Fortschr Röntgenstr 2012; 184: 1020-1025 